
et dans les oeuvres de ses contemporains

\title{
Avant de répéter La Tempête
}

\section{François Marthouret}

Marie-Thérèse Jones-Davies (éd.)

\section{(2) OpenEdition Journals}

\section{Édition électronique}

URL : http://journals.openedition.org/shakespeare/140

DOI : $10.4000 /$ shakespeare. 140

ISSN : 2271-6424

Éditeur

Société Française Shakespeare

Édition imprimée

Date de publication : 1 novembre 1980

Pagination : 156-158

\section{Référence électronique}

François Marthouret, «Avant de répéter La Tempête », Actes des congrès de la Société française Shakespeare [En ligne], 2 | 1980, mis en ligne le 01 novembre 2007, consulté le 01 mai 2019. URL : http://journals.openedition.org/shakespeare/140; DOI : 10.4000/shakespeare.140 


\section{SOCIÉTÉ FRANC̣AISE SHAKESPEARE}

\section{ACTES DU CONGRĖS 1980}

DIRECTEUR DE LA PUBLICATION

M.T. Jones - Davies

JEAN TOUZOT Libraire - Editeur 38 , rue Saint-Sulpice 75278 PARIS CEDEX 061981 


\title{
VENDREDI 14 NOVEMBRE
}

\author{
"Avant de répéter La Tempête», rencontre avec \\ François Marthouret.
}

Les traductions existantes ne nous fournissaient pas le matériau dont nous avions besoin. Avec François Barthélémy nous avons donc refait une traduction. J'avais déjà participé avec Peter Brook et Jean-Claude Carrière à ce type de travail. Au côté de ce dernier, il était passionnant d'aborder une traduction n'ayant pas pour objet de commenter, mais d'accepter la richesse des propositions et la multiplicité des significations. Notre souci est d'obtenir un texte doté d'efficacité instrumentale sans ambition littéraire ou conceptuelle.

La Tempête est d'une construction symbolique infiniment complexe. On peut, à la lire, éprouver dans un premier temps un sentiment d'ennui ou la trouver de facture banale. Le langage n'y foisonne pas aussi somptueusement que dans Lear et Macbeth, où les métaphores sont déchâ̂nées. La Tempête est d'une langue plus coulante. On comprend que la traduction puisse s'y noyer et s'abîmer dans sa propre contemplation, oubliant par là même la finalité de la représentation théâtrale. Ce qui nous importe, c'est de garder la vie et le rythme de cette langue qui a pour vertu d'inspirer à l'acteur l'improvisation de la pensée, une pensée qui s'invente sans cesse, qui est action. Nous nous efforçons bien sûr d'obtenir un texte qui soit idéalement le plus proche de celui du poète mais en optant pour la simplification, afin de permettre à l'acteur, grâce à son don de vie, de suggérer un écho à l'évocation des symboles, fussent-ils «intraduisibles».

La Tempête défie toute interprétation a priori. Il apparaît vain de vouloir décider à l'avance d'une signification globale. Nous entendons simplement porter témoignage à travers l'œuvre, sur la sensibilité d'un groupe. Le travail de répétition ne se résout pas à illustrer une thèse sur la pièce. Il consiste plutôt à animer un groupe en lui proposant une série d'interprétations. Il faut rester à l'écoute de ce que l'acteur propose. Dans son corps, sa voix, sa perception aux aguets, l'acteur se prépare à raconter une histoire, à prendre le risque du théâtre dans l'instant. C'est l'inverse 


\section{Actes du Congrès 1981}

d'une conception mentale de l'art théâtral. Je me veux plus artisan que démiurge. Avec cette première réalisation ambipar les acteurs. qui me justifierait.

L'idéal serait une proposition de base du décorateur qui puisse être battue en brèche au fur et à mesure des répétitions. J'aurais voulu que l'île soit en creux, que tout se joue dans un puîts (de vérité). L'île de Prospero, c'est à la fois le lieu d'élection magnifique de l'utopie, le no man's globe tout entier le dérouler le jeu terrible de la vérité, le nements. C'est l'île au âtre, siège des illusions et des retourtentant d'inventer un trésor et l'île maudite. Il serait l'imaginaire naiff des îles, f'e qui aille dans la direction de le plus possible illustrotiven produire des représentations appareil radar géant tives et symboliques : cirque, arène, doit permettre de signife d'araignée, aérolithe, le théatre Brook, je voudrais signifier tout cela. A la suite de Peter d'un acteur devant donner la priorité à l'essentiel, la parole ner à l'évocation plastique.

Claude

s'exprime en des-Strauss, à la fin de ses Mythologiques, Il évoque ce rien dispara tres proches de ceux de Prospero. sommeil comme andaissant en fumée qu'est l'existence, le affronter cette série d'illusio du néant, notre impuissance à et souligne que c'est justems en cascade qu'est le monde qui nous incite à tentertement cette conscience du néant monde. Voilà ce qui sans fin de donner un ordre à ce Quoi de plus émouvant touche le plus dans La Tempête. de Prospero, cet hommen effet que d'assister à l'expérience cohérence du monde de pouvoir qui tente de retrouver la politique et éthique, de refonder une légitimité d'ordre ration de l'être humain entreprend une orgueilleuse régénésinon poúr Dieu du moins le sens du Bien, qui se prend qui à la fin revient exactement l'ordonnateur du destin et changé. Personne n'est devent au point de départ? Rien n'a tion est en lui qui a perdu tou meilleur. La seule modificarassurante certitude qu'il y a une ses illusions. Il a perdu la ligence de l'univers et que le vérité absolue dans l'intell'emporter sur le Mal. Un bilan désen doit irrésistiblement derniers hommes al. Un bilan désespéré. Prospero, un des 
universelle, un magicien, un initiateur, un révélateur qui use de la Nature à son gré, le maître du jeu donc, ne s'y retrouve plus. Sa vision se heurte à la réalité.

Il y a dans l'épilogue ce cri admirable : «Rendez-moi la liberté». Etre enfin dans la réalité pour s'y abolir. Le dernier mot de Shakespeare est donc «liberté». La liberté de porter un autre regard sur le monde, la liberté d'affronter le réel dans toutes ses contradictions, une liberté qui s'ouvre sur la mort.

On peut considérer La Tempête comme le testament grandiose de Shakespeare. C'est pour moi la tragédie de Prospero. Elle montre combien ce jeu de vérité du théâtre n'est au fond qu'un songe. C'est pour cela qu'il renonce à ses pouvoirs de mage. Jusqu'à la jeune génération, pourtant élevée à l'abri, qui est pervertie. Les nouveaux rois de Naples, gentils tourtereaux au début, Shakespeare en deux lignes les voue à la mesquinerie.

Tout cela me paraît entrer en résonance avec ce qui nous hante aujourd'hui. Il reste à en témoigner dans l'acte charnel du théâtre. A l'acteur, toujours souverainement nu, si fragile et si fort, de porter le monde sur ses épaules.

François Marthouret 